\title{
The Digital Storywork Partnership: Community-centered social studies to revitalize Indigenous histories and cultural knowledges
}

\section{Authors: Christine Rogers Stanton, Brad Hall, and Jioanna Carjuzaa}

NOTICE: this is the author's version of a work that was accepted for publication in Journal of Social Studies Research. Changes resulting from the publishing process, such as peer review, editing, corrections, structural formatting, and other quality control mechanisms may not be reflected in this document. Changes may have been made to this work since it was submitted for publication. A definitive version was subsequently published in Journal of Social Studies Research, (September 2018) DOI\# 10.1016/j.jssr.2018.08.001.

Stanton, Christine Rogers, Brad Hall, and Jioanna Carjuzaa. "The Digital Storywork Partnership: Community-centered social studies to revitalize Indigenous histories and cultural knowledges." Journal of Social Studies Research (September 2018). DOI:10.1016/j.jssr.2018.08.001. 


\title{
The Digital Storywork Partnership: Community-Centered social studies to revitalize Indigenous histories and cultural knowledges
}

\author{
Christine Rogers Stanton (corresponding author) \\ Montana State University \\ PO Box 172880, Bozeman, MT 59717 \\ (406) 219-3898 \\ christine.rogers1@montana.edu
}

\author{
Brad Hall \\ Blackfeet Community College \\ bradfordr.hall@gmail.com
}

Jioanna Carjuzaa

Montana State University

carjuzaa@montana.edu

Keywords: Indigenous, documentary filmmaking, storywork, youth, community, participatory

Acknowledgements: The authors are grateful for the support and encouragement from our many partners and mentors: elders, teachers, students, community members, professional filmmakers, and tribal leaders. Key leaders and partners include Dr. Lucia Ricciardelli (Montana State University's School of Film and Photography), Cinda Burd, Eric Cox, Madison McClintock, and Jeffrey Rhyner. The Digital Storywork Partnership has been supported by grant funding from Humanities Montana, Montana State University (the Office of the Provost, the Office of the Vice President for Research and Economic Development, the Office of Outreach and Engagement, the Center for Bilingual and Multicultural Education, and the College of Education, Health, and Human Development). Additional support has been provided by Blackfeet Community College, Montana State University's School of Film and Photography, Montana State University's College of Arts and Architecture, Montana State University's Design Sandbox for Engaged Learning (DSEL), Heart Butte Schools, Buffalo Hide Academy, Browning Public Schools, the Little Shell Tribe, G and G Advertising, the Pryor $21^{\text {st }}$ Century Community Learning Center, and Plenty Coups High School. 


\section{The Digital Storywork Partnership: Community-Centered social studies to revitalize Indigenous histories and cultural knowledges}

\section{Introduction}

Since time immemorial, Indigenous ${ }^{1}$ communities have served as spaces for integrative learning that is grounded in unique knowledges, languages, and ways of knowing. However, early in the history of settler-colonialism in the Americas, formal schooling endeavored to disrupt community-centered learning and force assimilation of Indigenous peoples into EuroAmerican society. These approaches to schooling negatively affected - and continue to negatively affect — the social, physical, and cultural health of Indigenous communities while promoting false social studies discourses. To address the crises caused by over a century of deculturalizing education, Montana's Indian Education for All (IEFA) Act, an unprecedented effort over forty years in the making, was designed to 1) reduce bias against Indigenous peoples resulting from a lack of understanding, 2) enrich instruction by enhancing cultural relevance, and 3) (re)instill pride in cultural identity (Author, 2010).

In this article, we evaluate the potential for a model, the Digital Storywork Partnership (DSP), to advance IEFA and revitalize Indigenous histories, cultures, and identities within and beyond social studies ${ }^{2}$ classrooms. The DSP engages Indigenous and non-Indigenous youth, elders, college students, faculty, community members, and professional filmmakers in

\footnotetext{
${ }^{1}$ We encourage teachers, scholars, and advocates to use identifiers preferred by Indigenous peoples (e.g., Piikani). However, we recognize the complexity of this, as individuals may not have specific affiliations or they may prefer to identify using a more general term (e.g., Native). Furthermore, in some cases, widespread change and international action may be best supported through use of a collective term, particularly one that is broadly affirmed by scholars and leaders (e.g., Indigenous). Throughout this article, we use several different terms deemed appropriate for various contexts by our Indigenous partners.

${ }^{2}$ In this article, we recognize social studies as an expansive field that includes specific disciplines (e.g. history, geography, government, anthropology, sociology, economics), as well as interdisciplinary areas (e.g. ethnic studies) The DSP draws upon teaching and learning across social studies topics in a variety of formal and informal contexts.
} 
community-centered, place-conscious collaborative research and multimedia storytelling. The DSP was inspired by the work of Indigenous educators and scholars, especially Archibald's (2008) Indigenous Storywork, which connects learners actively and interactively with story. Importantly, Archibald emphasizes that stories carry essential cultural knowledges and that the transmission of those knowledges depends upon cultivation of a dynamic and meaningful relationship between the storyteller and the listener.

Since its inception six years ago, the DSP has supported five unique, ongoing projects with Piikani ${ }^{3}$ (Blackfeet), Apsáalooke (Crow), and Little Shell (Chippewa) communities across Montana. For example, one project focuses on recording oral histories and Chippewa conversations for language teachers to use in their K-12 classrooms. In another example, Apsáalooke youth who participate in an after-school partnership are researching responsible, ceremonial use of tobacco as a means to provide health education while revitalizing traditional knowledges. This article focuses on the Piikani Digital Histories, which engage Piikani high school and tribal college students in learning about Piikani histories. The DSP's growth is due primarily to word-of-mouth recommendations from members of these diverse Indigenous communities. In all cases, DSP facilitators were invited by and partnered with community members, including educators, elders, and other leaders, to develop and guide workshops focusing on integration of community-specific interests, cultural expectations, oral history research practices, and compelling filmmaking techniques. Workshops and related activities have taken place as part of high school, tribal college, and university courses, as well as through informal and extracurricular opportunities.

\footnotetext{
${ }^{3}$ Whenever possible, the DSP uses traditional names and spellings preferred by our specific Indigenous partners. It is important to note that such decisions are complex, given that there are frequently multiple spellings (e.g. Piikani, Pikuni, etc.) and accepted terms. As additional context for the case highlighted in this article, the Piikani are also known as Blackfeet, and the Blackfeet Nation is part of the larger Blackfoot Confederacy, which includes nations in Montana and Canada.
} 
While specific DSP elements are designed in collaboration with community partners and with each unique community context in mind, the model generally includes three phases. First, participants work together to define research interests and needs specific to the community. During this phase, community leaders provide guidance in terms of topics and cultural protocol, and film scholars and students introduce and model filmmaking practices. Additionally, this phase includes extensive discussion and practical experiences. Participants often use both familiar audiovisual technology (e.g., tablets, smartphones, iMovie) and more sophisticated filmmaking equipment (e.g., Canon EOS Rebel cameras, professional lighting and audio kits, etc.). The second DSP phase focuses on film production as a means to collect and analyze data. During this phase, small teams are created to ensure both technical and cultural expertise. In addition, cultural leaders are often consulted to ensure culturally appropriate filmmaking and research practices. Workshops are flexible to respond to team needs and provide individualized mentoring. The final phase involves sharing results with the community and beyond, as appropriate, according to cultural leaders and the participants.

This article describes a case study, which employed community-based participatory research (CBPR) and Indigenous research methodologies to evaluate the effectiveness of one DSP project, the Piikani Digital Histories. Before we share details related to this case study, we briefly describe how we, as educators and scholars, came to engage in community-centered research and the DSP, and we provide background information about the relationship between communities, Indigenous education, IEFA, and social studies.

\section{Coming to the DSP: Our Positionality}

A key expectation for research that applies CBPR and Indigenous methodologies is for the researchers to locate themselves within the community and research. In particular, we look 
to Kovach's 2013 work, which argues, “unpacking power and privilege as it applies (or does not) to Indigenous peoples and knowledges is a denotative function of transgressive pedagogies" ( $\mathrm{p}$. 117). Indigenous scholars, including Kovach, advocate for Indigenous leadership within Indigenous research and education, although Kovach (2013) also expresses the value of a "relational protocol between Indigenous and settler peoples" within such work, given the current numbers of non-Indigenous teachers and researchers (p. 116). One of the key goals of the DSP is to advance this relational protocol through opportunities for contributions from and learning by both Indigenous and non-Indigenous partners. However, Kovach emphasizes that "the relation of non-Indigenous educators to Indigenous pedagogy [and non-Indigenous researchers to Indigenous methodology] is complicated, even among those basically sympathetic and seeking to act in solidarity with Indigenous colleagues" (2013, p. 118).

Given this complexity, as DSP leaders and researchers, we strive to honestly view how our experiences and backgrounds inform and challenge our work and relationships with each other and with community partners. We also recognize the dynamic nature of relationships between community members and researchers and between Indigenous and non-Indigenous participants. As co-authors and leaders of the DSP, we are both cultural insiders (one of our team is a member of the Piikani Nation) and outsiders (two of us are non-Indigenous). Despite our different backgrounds, we are all committed to social justice education and have devoted the bulk of our careers to learning with and from Indigenous partners. We recognize the importance of teams that include Indigenous and non-Indigenous educators and researchers in order to advance an "ambidextrous consciousness" and to "problematize and disrupt normative practices" in today's schools (Kovach, 2013, pp. 114-115). 
Author 1, who is non-Indigenous, was raised in an upper middle class home in a predominantly White community in the Rocky Mountain region. Although her community was located less than two hours from a reservation, she rarely learned about Indigenous histories or contemporary experiences in her own schooling. She was introduced to social justice education through experiences working with migrant youth in urban and rural settings in the Midwest US in the 1990s. In 1999, she returned to her home state, where she worked as a teacher and instructional coach in schools on and bordering a reservation over the next decade. During this time, Author 1 began collaborating formally and informally with Indigenous community members, teachers, and elders. Her mentors helped expose the influence of Eurocentrism in her teaching and ways of interacting. For example, they emphasized the importance of listening instead of dominating conversations. After several years, these mentors encouraged her to engage in research that emphasized the strengths of Indigenous communities as a means to educate non-Indigenous educators, scholars, and community members. Following completion of her $\mathrm{PhD}$, Author 1 accepted a position at a land grant university, where she leads the social studies teacher education program and partners with Indigenous communities on various research efforts. For Author 1, DSP work with the Piikani community uniquely challenges her own history as a settler, as for several generations her family has farmed land bordering (and originally part of) the Blackfeet reservation. This family history becomes particularly relevant in terms of the history of education in the region, as the town where Author 1's grandmother attended school is the same town where Author 2's great grandfather boarded a train bound for the Carlisle Indian boarding school in Pennsylvania.

Oki nii-st-oo nii-taa-niiko Omak Saa-koo-ma-pi... Amp-skaa-pi Piikani. Author 2 was raised on the Blackfeet Indian Reservation in north central Montana, and his life experiences are 
grounded in his worldview as an Amp-skaa-pi Piikani. His great-uncle, Jim Spotted Eagle, gave him the name Omak Saa-koo-ma-pi, which in English means "Big Boy," and is a name that was held previously by Author 2's late grandfather Alvin Patrick Hall. In the Piikani culture, the process of naming serves to identify an individual who will commit—spiritually and collectively - to providing support for family, community, and nation. Piikani names also serve as a metaphorical guide for one's life. In Author 2's case, his name encouraged him to invest in researching Piikani history and the educational systems on the Blackfeet Indian Reservation. He recently completed his doctoral degree in educational leadership, a process that required him to realize the intersections between Piikani ways of knowing and mainstream "normative practices" of the academy (Kovach, 2013, p. 115). He continues to accept the challenges surrounding the furthering of Piikani research perspectives, protocols, and methods in order to strengthen his community and transfer Piikani knowledges to the next generation of Piikani researchers.

Author 3 has lived, studied, worked, traveled, and taught around the globe. While well versed in the many aspects of cultural diversity, linguistic diversity is her passion. In addition to English and her heritage Greek, she has studied French, Spanish, Italian, Russian, Chinese, and Nakoda languages. Diversity has played a key role in her personal and professional life, and she and her five siblings have each married partners from different cultures. She was the first in her family to graduate from high school. In her 25-plus years as a multicultural teacher educator and language instructor, she has had over 10,000 students and taught hundreds of courses promoting social justice and educational equity. Currently, she is a Professor at a land grant institution where she has provided IEFA leadership as a scholar and educator within Montana and beyond. She is committed to Indigenous language preservation and revitalization efforts and works closely with heritage language speakers. She continues to grapple with the intricate relationship 
between culture and language, as the key to identity, as well as help her Native students heal from the historical trauma inflicted by colonialism and assimilationist schooling. As an ally, she is grateful to serve peoples and communities across Indian Country.

Six years ago, Author 2 was teaching social studies in a school on the reservation and using oral history research to engage his students in learning about artifacts that had been recently repatriated to the tribe. When discussing that project with Author 1, we began exploring audiovisual technology as a way to support student-led research and social studies education while adhering to a community-specific cultural protocol. We worked with Indigenous scholars and oral historians from around the world, Piikani elders and cultural leaders, and critical film studies instructors to develop the DSP model. When Author 2 accepted a leadership position at the tribal college after the Fall 2013 semester, the DSP model was further refined through collaboration with the college's Piikani Studies Division. At that time, the DSP expanded to include students and faculty in the Film Studies program at a partner university. Two years ago, the DSP began collaborating with a research center on language revitalization efforts, and Author 3, who is Executive Director of the research center and had long provided DSP leaders with mentorship in terms of community-centered research and IEFA, joined the team.

\section{Background}

Community is more than a physical place, although it is often framed by a collective "place-conscious" understanding (Gruenewald, 2003). Relatedly, anthropologists, sociologists, and historians generally apply unifying elements of culture (e.g., languages, norms, practices, values/beliefs) to frame understandings of community (Hicks et al., 2016). Within Indigenous contexts, it is especially important to recognize the unique place-conscious and cultural interpretations of community, since "each Native community is distinguished by its own 
language, customs, religion, economy, historical circumstances, and environment" (Lomawaima, 2004, p. 442). While we recognize the complexity of culture and the cultural diversity within and between Indigenous communities, we also strive to acknowledge experiences shared by Indigenous communities across the Americas. In particular, we recognize the potential for peoples, places, and/or cultural practices to shape both individual and collective understandings of community. Often, these elements are intertwined in that the continuance of cultural practices depends upon participation of certain peoples (e.g., "knowledge carriers") and access to certain places (e.g., a sacred site).

The history of Indigenous education. Prior to invasion of the Americas by Europeans, millions of Indigenous peoples, representing thousands of diverse cultures and languages, populated the Western Hemisphere (Hixon, 2013). In some cases, Indigenous communities established permanent settlements, while in others they moved throughout large regions depending upon seasonal access to resources. For nomadic Indigenous peoples, community was defined and informed by many interconnected places and shared cultural knowledges. Learning was community-centered, place-conscious, and grounded in diverse languages that transmitted these specialized knowledges. As Henrietta Mann (Southern Cheyenne) explains,

If we look at the history of education as it affects the Indigenous peoples of the country, we really should, in all fairness, go back in time prior to 1492 and acknowledge the fact that Indigenous peoples had developed their own school systems. Then by the time a child ... matured to adulthood they were very capable, competent individuals who could speak their languages fluently, who knew their own history as a peoples, who were very skilled artisans. (The Montana Experience, 1:58) 
Throughout the Americas, colonization and settlement forced Indigenous peoples to redefine community and education. In the US, in particular, treaties were used to justify the removal of Indigenous peoples from traditionally significant places in order to expand settler access to Indigenous lands and resources (Hixon, 2013). This resulted in challenges related to the sustainability of place-specific cultural knowledges, as reservations are often located at a distance from or include only a small slice of traditional homelands.

The institution of formal education also served as a tool of disruption of traditional Indigenous education (Lomawaima, 2004). Throughout the late 1800s and well into the 1900s, thousands of Indigenous children were taken from their families and communities and relocated to boarding schools, where they were required to adopt the values and traditions sanctioned by the federal government (Haag, 2007). Under this forced assimilation model, all Indigenous cultural practices and languages were forbidden. Children were often beaten for speaking their languages and sent home ashamed of their communities and cultures. For many Indigenous peoples, language serves as the vehicle for specialized cultural knowledges, and without the language, transmission of unique histories, understandings, and worldviews is compromised.

As a result of whole generations facing forced assimilation, hundreds of Indigenous languages are now endangered, as are their essential roles in transmitting and sustaining placeconscious, cultural knowledges. Given this threat, national and international governing bodies have made efforts to preserve endangered Indigenous knowledges. The 1975 Indian SelfDetermination and Education Assistance Act officially ended the federal government's formal effort to force assimilation and expanded authority for tribes to revitalize Indigenous languages and knowledges (Lomawaima, 2004). In 1990, the US Congress passed the Native American Languages Act aimed at further protecting and promoting American Indian languages, and in 
November 2017, the Senate passed the Esther Martinez Native Languages Preservation Act. On an international scale, in 2007 the United Nations adopted the Declaration on the Rights of Indigenous Peoples, which recognizes that education designed to eradicate Indigenous languages and cultures is a basic violation of human rights (Warhol, 2011). Despite these policymaking strides, "there has been tremendous loss and the peril of extinction [of languages and their related cultural knowledges] looms ominous or threatening” (Littlebear, 2017).

Montana's Indian Education for All (IEFA). To address the urgent need for sustainability and revitalization of Indigenous languages and cultures, the state of Montana has committed to IEFA, a mandate which requires all teachers, regardless of student population, grade level, or content area, to teach about Montana's Indigenous nations, experiences, and perspectives. IEFA became a reality in large part because of leadership from youth, elders, and community members from Montana's politically active and diverse Indigenous communities. The state is home to twelve federally recognized Indigenous nations and the state-recognized Little Shell Tribe of Chippewa Indians. There are seven reservations within the state's borders, which are each sovereign, independent, and self-governing, with a unique status in the American federal system. While Montana boasts the highest percentage of speakers of five Indigenous languages, all eleven Indigenous languages in the state are critically endangered (U.S. English Foundation Inc., 2016).

Although it is ranked as the fourth largest state in the U.S. by land area, Montana is the seventh least populous state in the nation. The Indigenous population in this sparsely populated state $(6.6 \%)$ is substantially greater than the national average, and the preK-12 Indigenous student population, at $14 \%$, is more than ten times the national average (OPI, 2017). Approximately 92\% of Indigenous students in Montana attend regular public schools, most often 
located on or near reservations. These schools experience the greatest concentrations of poverty, low attendance, and high dropout rates of all Montana schools (OPI, 2017).

To address the educational challenges facing Indigenous peoples, Montana has long committed to two pillars of Indigenous education: 1) teaching all Montana students- both Indigenous and non-Indigenous — about the unique histories and cultures of Indigenous peoples, and 2) increasing the academic achievement of Indigenous students. According to Article X of the Montana constitution, which was established in 1972 in response to testimony from two Dakota youth (Juneau \& Smoker Broaddus, 2006), “The state recognizes the distinct and unique cultural heritage of the American Indians and is committed in its educational goals to the preservation of their cultural integrity" (Montana Constitution, 1972, Art. X, §1.2). It was not until 1999, however, that more clarity and direction regarding these "educational goals" arrived in the form of the legislative mandate known as IEFA, which requires educators across grade levels and content areas to teach all Montana students about the experiences of the state's Indigenous peoples (Mont. Code. Ann. ttl. 20, ch.1, pt. $5 \S 1$ 1999). IEFA's early efforts proved challenging, as there were few resources and professional development opportunities. In 2005, the state earmarked funding to expand development of curriculum and teacher training (Author, 2015a; Juneau \& Smoker Broaddus, 2006).

While there is still much debate around what constitutes excellent, culturally sustaining and revitalizing education for Indigenous children, leaders and scholars agree that it is critical to collaborate with Indigenous educators and tribal members and to support responsible and accurate integration of cultural knowledges, ways of knowing, and languages (McCarty \& Lee, 2014). As educational consultant Julie Cajune (Salish) explains, "Individual teachers can do phenomenal things, but nothing (in education is going to change systematically) ... until power is 
shared" (personal communication, July 23, 2010). To guide Montana's predominantly nonIndigenous educators in IEFA implementation, leaders from the state's twelve Indigenous nations collaborated in 1999 to develop a framework of "Essential Understandings" (EUs) (see Table 1), curricular materials, and lesson plans that integrate Indigenous perspectives across grade levels and content areas. As is true of many culturally sustaining and revitalizing educational efforts, IEFA's realization was, and continues to be, a dynamic process. While the EUs remain the same as originally worded in 1999, the OPI has released multiple versions of accompanying materials and information to more effectively represent the depth of histories, experiences, and perspectives of Montana's diverse nations.

The successes of IEFA have reverberated around the globe, and Montana is often viewed as a leader in broad-scale efforts to advance Indigenous education (Author, 2015a; Smiley \& Sather, 2009). Several other states have based their own state-level policies and frameworks on IEFA, although no other state's work is as comprehensive. Efforts like IEFA offer substantial benefits, as they encourage retention of teachers of color (Achinstein, Ogawa, \& Sexton, 2010), increase historical accuracy (Banks \& Nguyen, 2008; Bennett, 2001), and support enhanced use of culturally responsive pedagogy by and professional development for White teachers (Author, 2010; Author, 2012; Goldenburg, 2014). Since identity is a key factor in student achievement, implementing culturally sustaining and revitalizing pedagogy and preserving Indigenous languages, histories, and knowledges offers tremendous potential to narrow the achievement gap between Indigenous and non-Indigenous students (Author, 2015a; McCarty \& Lee, 2014).

IEFA and social studies education. Despite its emphasis on social interactions, histories, and cultures, social studies has largely fallen short of supporting culturally sustaining and revitalizing education. Social studies textbooks, teachers' guides, standards, and other 
curricular resources typically misrepresent Indigenous experiences (Author, 2014; Author, 2015b; Journell, 2009; Levstik \& Barton, 2010; Loewen, 1995, 2010; Sanchez, 2007; Shear, Knowles, Soden, \& Castro, 2015). Films, which are also popular resources in social studies classrooms, often reinforce these inaccurate and negative stereotypes (Seixas, 2007; Stoddard, Marcus, \& Hicks, 2014). Furthermore, the literature demonstrates that teachers rely heavily on these biased curricular resources to guide their instruction (Author, 2015b; Powell, 2017; Whitney, Golez, Nagel, \& Nieto, 2012).

The bulk of research has focused on the representation of Indigenous peoples within history curricula, with limited attention given to other social studies disciplines (e.g., geography, government/civics), largely because those other areas are even less likely to include Indigenous experiences. Broadly, the resulting messages for teachers and students are that Indigenous experiences and perspectives belong in the pre-1900 past (if they are included at all), Indigenous peoples and governments are primitive and dependent (even in the modern context), and Indigenous worldviews conflict with economic progress. Furthermore, social studies resources typically suggest that genocide, forced relocation, and the resulting poverty resulted from an unstoppable "destiny" that favored European and Euro-American worldviews, rather than from intentional actions by settlers and government leaders (Author, 2014).

Although IEFA is intended to be implemented across content areas, it is especially well suited for social studies education given its efforts to expose the underlying Eurocentric, settlercolonial bias within mainstream curricula and to transform education by including counternarratives by Indigenous leaders and critical historians. For example, EU 6 explains:

History is a story most often related through the subjective experience of the teller. With the inclusion of more and varied voices, histories are being rediscovered and revised. 
History told from an Indian perspective frequently conflicts with the stories mainstream historians tell. (OPI, 2012)

Within social studies education, curricular transformation benefits all Americans as we work toward building a democratic and just society. In particular, an inclusive, multicultural history curriculum develops deep understandings of context and promotes connection-making between the past and the present, as noted by Mehan, et al. (1995):

A multicultural history curriculum, by focusing on the experiences of men and women of diverse racial, ethnic, and religious groups in United States history, will provide students with a historical context in which to situate and understand the experiences and perspectives of these groups in American society today. (p. 133)

Beyond history education, the IEFA EUs offer expansive guidance for teachers of other social studies areas. For example, EU 3 recognizes that "The ideologies of Native traditional beliefs and spirituality persist into modern day life as tribal cultures, traditions, and languages are still practiced by many American Indian people and are incorporated into how tribes govern and manage their affairs" (OPI, 2012). This EU, like many of the others, uses present tense to emphasize the continued influence of Indigenous worldviews, and it demonstrates the potential for meaningful integration within government/civics, as well as history. Similarly, EU 7 (“Under the American legal system, Indian tribes have sovereign powers, separate and independent from the federal and state governments") supports complex learning for students studying government/civics. EU 4 ("Reservations are lands that have been reserved by the tribes for their own use through treaties, statutes, and executive orders and were not 'given' to them") offers the potential to promote geographical inquiry. Each of the EUs provides opportunities for rich, interdisciplinary learning, as evidenced by EU 5: 
There were many federal policies put into place throughout American history that have affected Indian people and still shape who they are today. Many of these policies conflicted with one another. Much of Indian history can be related through several major federal policy periods. (OPI, 2012)

This EU supports teaching and learning about history (the Essential Understandings guide identifies six "policy periods" spanning 1492-present), government/civics (e.g., treaty, tribal reorganization, termination/relocation, and self-determination periods), geography (e.g., colonization, treaty, assimilation/allotment, and termination/relocation periods), and economics (e.g., colonization, assimilation/allotment, and self-determination periods).

IEFA has transformed social studies education within Montana in several ways. It led to the development of a textbook, Montana: Stories of the Land (2009), which presents Indigenous perspectives not as sidebars, but as integrated throughout the text. The Montana Office of Public Instruction offers vast IEFA resources that align with social studies standards. While the online social studies repository includes lessons and materials surrounding popular history topics such as fur trade and Thanksgiving, it also includes lessons focusing on critically oriented topics, such as Indigenous views of colonization, boarding school experiences, identifying and responding to contemporary stereotypes, and using primary sources to understand tribal sovereignty (OPI IEFA Social Studies Lesson Plans and Resources, n.d.).

Beyond Montana, IEFA and its related support structures have influenced social studies education in several notable ways. First, IEFA itself served as a model for several other states that have adopted similar curricular frameworks focusing on Indigenous histories, experiences, and worldviews. Montana recommended several changes to the College, Careers, and Civic Life (C3) Framework for Social Studies State Standards (2013), a resource that informs curricular 
decision-making on a national level, including the addition of "tribal government” to suggested pathways guiding civics education. Montana’s Indian Education Division provided support and inspiration for a National Council for Social Studies resolution to support greater inclusion of Indigenous experiences throughout social studies education. Teachers from across the country access and use the IEFA resources that are publicly available on the OPI website.

Although there are countless approaches to IEFA, they vary in terms of potential to support culturally sustaining and revitalizing pedagogies. Paris (2012) argues that teachers should move beyond "culturally relevant" education to practices that actively cultivate and sustain cultural understandings. In other words, teachers may believe that simply adding information about diverse cultures to their existing, Eurocentric curriculum is adequate. However, as Paris and other critical multicultural scholars argue, a more dedicated effort by teachers is needed. Instead of simply adding "relevant" content, teachers need to actively participate in the comprehensive transformation of their curricula and pedagogy to sustain diverse knowledges and ways of knowing (Banks, 2014; Paris, 2012; Sleeter \& Grant, 2009). Indigenous scholars McCarty and Lee (2014) recommend that teachers need to engage their students in revitalization of endangered languages and understandings.

\section{Methodology}

To evaluate the potential for the DSP to sustain and revitalize Indigenous knowledges and ways of knowing within social studies education, we apply a combination of communitybased participatory research (CBPR) (Author, 2014; Northway, 2010), Indigenous research (Kovach, 2009; Smith, 1999; Wilson, 2008), and case study (Stake, 1995) methodologies. The DSP is itself a realization of community-centered research, as each film is created using a synthesis of CBPR and Indigenous research praxis. Furthermore, our case study of digital 
storywork as pedagogy provides deeper insight to the potential for community-centered education to sustain and reinvigorate traditional knowledges within and beyond social studies. Therefore, our commitment to participatory research design extends across the phases of DSP projects, as well as data collection and analysis related to the DSP model evaluation.

Context and Participants. The DSP case described in this article focuses on the Piikani Digital Histories, which began as part of a final project for an $11^{\text {th }}$ grade U.S. History course taught by Author 2 during the Fall of 2013. The project evolved over the next four years to involve over 40 individuals, including Piikani youth in two high school settings, Piikani students and faculty from the tribal college, and Piikani community members and elders, as well as nonIndigenous university faculty, Film Studies students, and professional filmmakers. The DSP model endeavors to engage participants in collaboration during both technical processes (e.g., editing footage) and cultural decision-making (e.g., following interview protocol). For example, Piikani partners taught the non-Indigenous Film Studies students about cultural histories and protocol while the non-Indigenous Film Studies partners provided technical coaching. Although the partnership is reciprocal, it is important to note that the Piikani participants retained control over all major decisions related to content, process, and final products. Additionally, in the case of Piikani Digital Histories projects, decisions about film topics, editing, and dissemination demanded frequent, ongoing consultation with community leaders.

The Piikani Digital Histories leadership team also grew over time, beginning with Authors 1 and 2, and adding a non-Indigenous faculty member from the university's School of Film and Photography in 2015 to provide technical and artistic filmmaking expertise and Author 3, who is an expert in language revitalization and IEFA, in 2016. Importantly, many leadership decisions have been made collaboratively with Piikani leaders and educators. For example, 
participants and DSP leaders worked with Blackfeet Nation Institutional Review Boards and Piikani tribal leadership, elders, and cultural experts to determine appropriate forms of data, approaches to analysis, and methods for dissemination. Two Piikani tribal college students, who participated in the first workshop series, joined the leadership team in 2016 and helped design and facilitate workshops for teachers (both Piikani and non-Indigenous) and Piikani youth. These students also contributed to presentations and publications related to the DSP model. DSP projects apply a "5 R" Framework synthesizing work from scholars (Archibald, 2008; Kirkness \& Barnhardt, 2001; Wilson, 2008) with community-generated guidelines to center Indigenous views of respect, relevance, reciprocity, responsibility, and relationality. Early in the project, participants decided to add a sixth " $\mathrm{R}$ " (representation), due to previous audiovisual misrepresentations of Piikani histories and experiences. As participants and DSP leaders engaged in various aspects of the research process, we regularly referred to the $6 \mathrm{R}$ Framework to ensure we were meeting community expectations. Although DSP workshops introducing the basics of research and filmmaking often take place in tribal college or high school classrooms, much of the learning occurs outside of the conventional classroom spaces, and it is in these contexts that the $6 \mathrm{R}$ Framework becomes especially important. For example, Piikani Digital Histories projects have included community-based research conducted in ceremonial rooms at the tribal college, on cliffs overlooking the site of the Bear (Marias) River massacre, and in the homes of elders.

Data sources and analysis. As the purpose of this article is to describe the DSP in terms of its potential to advance revitalization of Indigenous histories, cultures, and languages, both within and beyond formal social studies classrooms, we sought to synthesize data from across diverse contexts and participants. Data sources included interviews with community members 
and participants; observations of workshops, film production activities, and planning/debriefing sessions; journaling and researcher field notes; and film products. Data analysis consisted of four phases: 1) open coding adhering to widely accepted qualitative practices (Emerson, Fretz, \& Shaw, 1995; Rubin \& Rubin, 2005), 2) collaborative coding during film editing (Authors, 2016), 3) participatory sense-making during planning and debriefing sessions (De Jaegher \& Di Paolo, 2007), and 4) focused coding to integrate IEFA EUs.

The DSP embraces multiple opportunities for collaborative meaning-making, which is important for participatory research that engages both community insider and outsider coresearchers (Author, 2014). Open coding procedures allowed the DSP leaders and participants to identify repeated descriptors that emerged from the various data. Then, as the DSP participants prepared audiovisual data for their films, they engaged in qualitative coding practices by responding to questions (e.g., "What are the central ideas and stories that emerged across interviews?", "What data should be included/excluded, and why?"). They also practiced thematic coding by organizing edited footage by theme within the films (e.g., "School," "Family Connections," etc.). Similarly, participants engaged as co-researchers when reviewing data related to observations and interviews. In several cases during the open and collaborative coding phases, the DSP participants identified themes or codes overlooked by the DSP leaders.

Since the DSP involves Indigenous and non-Indigenous youth, college/university students, faculty and staff, and community members, and spans disciplines and professions across social sciences, humanities, and audiovisual media, we remain sensitive to the challenges that surround meaningful inclusion of various participants throughout analysis (Author, 2014). Therefore, our analysis and the continuous refinement of the DSP model is largely dependent upon "participatory sense-making" practices that align with work by social cognition scholars De 
Jaegher and Di Paolo (2007, p. 489). In essence, participatory sense-making relies upon interaction between two or more autonomous actors in order to collectively create meaning. During meals, gatherings in homes, and hours-long car rides to or from research and production sites, we engaged in conversations with each other, students, community members, elders, educators, and cultural leaders about the data and emerging understandings. These "sensemaking" sessions provided culturally grounded insight and were complex in their diversity and scope. For example, interpretations of data varied given a co-researcher's age, cultural identity, experience with traditional knowledges, and formal education level.

Finally, to frame the complex results within the context of culturally revitalizing education and social studies, we applied focused coding using the IEFA EUs. Although IEFA is intended for use across content areas, it is particularly popular within social studies, it is relevant to our Montana context, and it offers a framework that is familiar to many of the DSP partners. Furthermore, as several states have looked to IEFA as they have revised their own social studies standards, the EUs offer a practical guide for analysis and application beyond Montana.

\section{Results and Discussion}

Piikani Digital Histories participants have created two publically accessible films, as well as several other videos that are shared within approved settings such as local schools and/or culturally appropriate contexts. Full Circle, the first film, introduces the importance of preserving and reinvigorating Blackfeet history, culture, and language, and has been screened locally, at state professional development conferences, and at the annual convention of the American Educational Research Association. It is also included in the curriculum for Indigenous studies and social studies methods courses at the tribal college and two universities. A second film, Bear River, focuses on an 1870 massacre that resulted in more than 200 Piikani deaths and 
on annual commemoration events held in honor of the massacre survivors. The final version of this film is still in production, but parts have been shared locally, with some footage even contributing to a local newscast. A version of the film was recently submitted to an Indigenous documentary filmmaking contest. Below, we describe the ways that these projects support culturally revitalizing education, develop complex conceptual awareness of community, and honor individual and cultural identities.

Revitalizing cultural knowledges for social studies learning. Participants noted that the DSP process allowed them to learn about, deconstruct, and challenge stereotypes. Conversations with one team revealed recognition of the need to "confront [the] poverty porn" that is rampant within documentary and fiction film representations of Indigenous experiences. Both Piikani and non-Indigenous team members agreed that although it is important to highlight the real challenges facing Indigenous communities, it is critical to do such work responsibly and without striving for a "shock appeal" merely to achieve notoriety for the filmmaker(s).

The research, cultural education, and filmmaking experiences that surrounded Full Circle's development supported multiple IEFA EUs, especially EU 1 (“”...Each Nation has a distinct and unique cultural heritage"), EU 3 ("The ideologies of Native traditional beliefs and spirituality persist into modern life as tribes, cultures, traditions, and languages are still practiced"), and EU 5 ("federal policies...have affected Indian people and still shape who they are today"). For example, the Full Circle filmmakers conducted interviews about historical trauma and the role of language in "carrying" historical knowledges. They also worked closely with elders and cultural leaders to discuss interview data and analyze archival photographs. For example, team members learned about the unique markings on Piikani tipis, which were unique not only to the tribe, but to specific families. 
Research related to Bear River generated learning about treaties (EU 5), reservations (EU 4), and the continued importance of cultural and linguistic knowledges (EU 3). For example, production of the film required special permission and travel on unimproved roads to access a ceremony located at the remote massacre site. Additional footage was collected during a 70-mile tribute ride in blizzard conditions, when several Piikani riders retraced the journey of massacre survivors on horseback. These experiences resulted in enhanced understanding of the unique historical and geographic influences that affected, and continue to affect, the Piikani Nation.

As another example, participants who worked on Bear River learned that prior to the invasion of Euro-American settlers, grizzly bears migrated across the plains by following "Bear River," which was renamed the "Marias River" after Meriweather Lewis' cousin, Maria. With increased White settler activity, the bears were forced to stay in the mountains year round. However, with climate change affecting food sources and habitat today, today the bears are once again moving out onto the plains during certain times of the year. This example demonstrates how settler-colonial "naming and claiming" methods affected the environment, and it illustrates the urgency of revitalizing cultural histories, particularly as related to languages and place names, in order to better understand climate change impacts on local geography and migration.

In addition to revitalizing specific cultural knowledges through the content of film projects, the DSP process demonstrates the potential to revitalize Piikani ways of knowing. On several occasions, Piikani Digital Histories participants noted the alignment of community-based research, filmmaking, and digital storywork with traditional storytelling practices and EU 3: The ideologies of Native traditional beliefs and spirituality persist into modern day life as tribal cultures, traditions, and languages are still practiced by many American Indian people and are incorporated into how tribes govern and manage their affairs. 
Additionally, each tribe has its own oral histories, which are as valid as written histories. These histories pre-date the "discovery" of North America. (OPI, 2012)

For example, a Piikani tribal college student noted that the DSP process is different from history textbook accounts in its attention to "recreating the oral tradition." Multiple participants, including elders, agreed that the use of film allows learners to see and hear the storyteller, which is important for building relationships and understanding.

Developing complex awareness of community. Both film projects provided opportunities for participants to develop deeper awareness of community, particularly as related to thinking about access to traditional, collective knowledges. Throughout their work on Bear River, the production team learned about the breadth of perspectives within the community, including within their own team, which aligns with IEFA EU 2:

There is great diversity among individual American Indians as identity is developed, defined and redefined by entities, organizations and people. A continuum of Indian identity, unique to each individual, ranges from assimilated to traditional. There is no generic American Indian. (OPI, 2012)

When working on Bear River, a Piikani college student emphasized that his "own interpretation" of how to represent the massacre could encourage collective healing. Another Piikani team member, however, argued that "with a massacre, there can never really be healing." This realization mirrored tensions within the community, as some community members expressed interest in the film's creation as a way to encourage healing, while others said they did not want to draw attention to the massacre or its commemoration at all, preferring instead to "just move on from that [horrible event]." 
Since stories and perspectives can be personal, collective, or a mix, the Piikani Digital Histories projects also provided insight to EU 6:

History is a story most often related through the subjective experience of the teller. With the inclusion of more and varied voices, histories are being rediscovered and revised. History told from an Indian perspective frequently conflicts with the stories mainstream historians tell. (OPI, 2012)

For example, as a Piikani tribal college student, Piikani high school student, and non-Indigenous filmmaker discussed two conflicting interviewee's accounts when editing Full Circle, they noted an added "collective responsibility" within the DSP model. They agreed that researchers and filmmakers who strive to implement digital storywork with integrity within Indigenous communities need to distinguish between personal accounts, opinions, and stories that represent tribal history or a collective understanding.

Explicit attention to Indigenous leadership in decision-making proved critical and successful. For example, during an editing workshop, a non-Indigenous Film Studies student reiterated to his Piikani co-researchers, "Now that the footage is all in [the computer's film editing program] and you know the basics about the software, it's up to you to figure out how to tell the story. It's your story." Both Full Circle and Bear River highlighted the complexity of governance and leadership within Indigenous communities, as participants recognized that in addition to Piikani Nation Institutional Review Board approval, projects also needed guidance from leaders outside of the tribal college and tribal government. This awareness advances nuanced learning related to EU 7 ("Under the American legal system, Indian tribes have sovereign powers, separate and independent from the federal and state governments"). 
The team that consisted of a Piikani high school youth, a Piikani tribal college student, and a non-Indigenous professional filmmaker demonstrated the importance of building small teams that include members with a range of cultural expertise and community connectedness. The high school student on this team expressed anxiety about "not having living grandparents" to teach her about cultural knowledges. As a result of this conversation, the tribal college student, who is well-connected to many elders in the community, offered to accompany the high school student on interviews, to introduce her to knowledge carriers, and to serve as an informal cultural mentor outside of the classroom.

Honoring complicated identities. Finally, the Piikani Digital Histories projects demonstrated the potential to develop deep understanding of identity, both in terms of tribal nation identity (EU 1) and individual identity (EU 2). Our teams included both Piikani and nonIndigenous participants, but they were also purposefully intergenerational and inclusive of members with varying comfort levels in terms of cultural and technical expertise. For example, one team included an elder, three non-Indigenous Film Studies students, and two Piikani tribal college students, one of whom identified as "traditional", while the other had been raised away from the reservation and did not have much traditional understanding coming into the project. In this team, the elder and one of the tribal college students demonstrated leadership in terms of traditional Piikani knowledges and cultural protocol, while the Film Studies students and the other tribal college student provided technical filmmaking leadership.

While one participant, a Piikani high school student, believes community members will always question the motivations of researcher and filmmakers, she noted that decisions related to identity, counter-narratives, and collective responsibility are especially complicated in Indigenous communities. For example, she explained that using her last name, which clearly 
identifies her as a Native person, can offer a competitive "edge" when submitting work to outlets seeking "diverse authors or filmmakers." However, she argued that taking advantage of that edge can "leave a bad taste in your mouth," if the main purpose is for the outlet to "look good." As this team discussed, the complexity of identity within Indigenous communities, where some people identify as "traditional" and many identify with both traditional and assimilated elements, makes questions related to identity, motivation, responsibility, reciprocity, and cultural appropriation even more challenging.

These powerful discussions about national and individual identities clearly connect to EU 1 ("There is great diversity among the twelve tribal nations of Montana in their languages, cultures, histories and governments") and EU 2 (“... A continuum of Indian identity, unique to each individual, ranges from assimilated to traditional"). Piikani Digital Histories participants agreed that within Indigenous communities, and within the DSP, there seems to be an added tension surrounding identity. As one Piikani tribal college student asked, "why does it have to be either you 'walk in two worlds' or you don't?"

\section{Implications and Recommendations}

The Piikani Digital Histories projects demonstrated potential to support IEFA integration and powerful social studies education, but they also exposed multiple areas of challenge that can inhibit culturally revitalizing education. In particular, we learned that digital storywork takes extensive time, which limits its applicability within conventional school calendars, as participants need time to learn about, engage with, and re-envision research practices, complex histories and cultural perspectives, and technical filmmaking skills. Each of these areas typically requires a substantial learning curve that is further complicated in diverse teams. To address these challenges, we recommend that teachers have plans in place to ensure sustainability across 
periods, semesters, and academic years. For example, partnering with after-school or summer programs, or integrating digital storywork across multiple content areas, might provide a way to support participation outside of mainstream social studies class schedules. We have found success in providing stipends and other support for participants to engage in intensive institutes beyond the conventional school calendar.

Similarly, we encourage respectful storywork that extends beyond the classroom not only in terms of time, but also in terms of place. The most powerful learning that resulted from the Piikani Digital Histories occurred in community settings, at historical sites, and/or in informal contexts such as cars, homes, or restaurants. However, classroom environments did play a role in the DSP. We found such settings helpful for demonstrations, discussion of technical basics and film theory, and some planning efforts. We also learned that in some cases, including one of the high schools, students and teachers may be discouraged from engaging in digital storywork efforts that occur beyond the school building. Such discouragement may be the result of limited resources, but it may also signal concerns about participant safety and/or community perception. For example, many of the sites included in Piikani Digital Histories films are difficult to reach even during the most favorable weather conditions. While winter filming of the Bear River massacre site boosted historical accuracy, accessing the site came with significant risks. In our case, all members of the film production team that traveled to the site and that shot footage of the tribute ride were over the age of eighteen. We recommend that teachers and scholars, especially those working with minors, collaborate closely with tribal institutional review boards, school leaders, family members, and students to determine the safest ways to access locations that are not based at the school. Similarly, teachers and scholars should learn about and respect the 
sacredness of places. "Place-conscious" digital storywork requires an understanding of the specific cultural expectations surrounding the places included in research and filmmaking.

The Piikani Digital Histories project also taught us to recognize the importance of sustained relationality with/in the community. In particular, the DSP encourages "multisensory listening" (Brayboy et al., 2012, p. 441), which supports learning with community members throughout the storywork processes. Such work, while a central component of Indigenous research and culturally revitalizing pedagogy, inherently requires time and trust. Semester- or year-long courses are often not adequate in terms of developing meaningful and trusting partnerships, particularly when sensitive cultural information is being shared. We also recognize that DSP projects offer one step toward cultural or linguistic revitalization, but that they do not in and of themselves generate such revitalization. Therefore, we encourage teachers to guide students in digital storywork that builds upon earlier projects. Finally, since many elders and knowledge carriers have traumatizing memories of formal educational institutions such as boarding schools, trusting collaboration often requires meeting with leaders outside of school walls. Schools can support digital storywork and culturally revitalizing education more broadly by identifying and compensating cultural mentors and by connecting teachers, students, and scholars with community partners in settings chosen by the community members.

\section{Conclusion}

Long before European contact, Indigenous peoples in the Americas designed and refined their own culturally sustaining educational systems. Beginning early in the history of the US, efforts to suppress Indigenous peoples and remove them from land desired by White settlers expanded rapidly. When the systematic eradication of Indigenous peoples failed, boarding 
schools were established to dissolve the family unit and strip Indigenous peoples of their cultural pride by forbidding their languages, ignoring their knowledges, and prohibiting their spirituality.

As a result of these settler-colonial efforts, Indigenous peoples were forced to re-envision community and education within new contexts. Contemporary Indigenous communities are not solely defined geographically, since reservations may be located a distance from traditional lands and since many Indigenous peoples live off reservation. For modern Indigenous peoples, community encompasses a comprehensive appreciation of shared cultural aspects including histories, languages, values/beliefs, cultural practices, and a commitment to collaborative meaning-making and activism. Today, many Indigenous communities are working to revitalize traditional knowledges and ways of knowing within and beyond formal school contexts.

Revitalization efforts within schools are difficult, since Eurocentric perspectives remain dominant — especially in social studies education — and myths and misconceptions are easily perpetuated. In an effort to confront curricular bias, Montana has led the way with IEFA, which was designed to educate all Montana students about the unique histories and cultures of Indigenous peoples while boosting the academic success of Indigenous students. Although there is no single approach to successful implementation of IEFA, guidance from Indigenous elders, leaders, and community members has been a vital and unifying aspect.

The DSP is one model striving to support community-centered education, inclusion of IEFA EUs, and meaningful social studies learning. The case described in this article demonstrates the DSP's potential to support deep historical and geographic awareness not necessarily possible within the constraints of a typical classroom environment or curriculum. Overall, the DSP enhances culturally affirming and revitalizing education, community-connectedness, and identity development within Indigenous communities, and its 
model holds promise for use in all communities given its effectiveness in advancing content accuracy, place-conscious education, and multicultural learning. 


\section{References}

Achinstein, B., Ogawa, R. T., Sexton, D., \& Freitas, C. (2010). Retaining teachers of color: A pressing problem and a potential strategy for "hard-to-staff" schools. Review of Educational Research, 80(1), 71-107.

Archibald, J. (2008). Indigenous storywork: Educating the heart, mind, body, and spirit. Vancouver: UBC Press.

Author (2010).

Author (2014).

Author (2015a).

Author (2015b).

Authors (2016).

Banks, J.A. (2014). An introduction to multicultural education (5 $5^{\text {th }}$ ed.). Boston, MA: Pearson Education.

Banks, J.A., \& Nguyen, D. (2008). Diversity and citizenship education: Historical, theoretical, and philosophical issues. In L.S. Levstik \& C.A. Tyson (Eds.), Handbook of research in social studies education (pp. 137-151). New York: Routledge.

Bennett, C. (2001). Genres of research in multicultural education. Review of Educational Research, 71(2), 171-217.

Brayboy, B. (2005). Toward a tribal critical race theory in education. The Urban Review, 37(5), 425-446.

Brayboy, B., Gough, H., Leonard, B., Roehl, R., \& Solyom, J. (2012). Reclaiming scholarship: Critical Indigenous research methodologies. In S. Lapan, M. Quartaroli, \& F. Riemer 
(Eds.), Qualitative research: An introduction to methods and designs (pp. 423-450). San Francisco: Jossey-Bass.

C3 Framework for Social Studies State Standards (2013). National Council for the Social Studies: Silver Spring, MD. Retrieved from http://www.socialstudies.org/c3

De Jaegher, H. \& Di Paolo, E. (2007). Participatory sense-making: An enactive approach to social cognition. Phenomenology and the Cognitive Sciences, 6, 485-507.

Emerson, R. M., Fretz, R. I., \& Shaw, L. L. (1995). Writing ethnographic fieldnotes. Chicago: University of Chicago Press.

Goldenberg, B. M. (2014). White teachers in urban classrooms: Embracing non-White students' cultural capital for better teaching and learning. Urban Education, 49(1), 111-144.

Grande, S. (2008). Red pedagogy: The un-methodology. In N. K. Denzin, Y. S. Lincoln, \& L. T. Smith (Eds.) Handbook of critical and Indigenous methodologies (pp. 233-254). Los Angeles, CA: Sage.

Gruenewald, D. A. (2003). Foundations of place: A multidisciplinary framework for placeconscious education. American Educational Research Journal, 40(3), 619-654.

Haag, A. M. (2007). The Indian Boarding School era and its continuing impact on tribal families and the provision of government services. Tulsa Law Review, 43(1), 149-168.

Hicks, C., Levine, A., Agrawal, A., Basurto, X., Breslow, S., Carothers, C., . . Levin, P. (2016). Engage key social concepts for sustainability. Science, 352(6281), 38-40.

Hixon, W. (2013). American settler colonialism: A History. New York: Palgrave McMillan.

Journell, W. (2009). An incomplete history: Representation of American Indians in state social studies standards. Journal of American Indian Education, 48(2), 18-32. 
Juneau, D., \& Smoker Broaddus, M. (2006). And still the waters flow: The legacy of Indian Education in Montana. The Phi Delta Kappan, 88(3),193-197.

Kirkness, V. J., \& Barnhardt, R. (2001). First Nations and higher education: The four R'sRespect, relevance, reciprocity, responsibility. In R. Hayoe \& J. Pan (Eds.) Knowledge across cultures: A contribution to dialogue among civilizations. Hong Kong: The University of Hong Kong. Retrieved from http://www.ankn.uaf.edu/IEW/winhec/FourRs2ndEd.html

Kovach, M. (2009). Indigenous methodologies: Characteristics, conversations, and contexts. Toronto: University of Toronto Press.

Kovach, M. (2013). Treaties, truths, and transgressive pedagogies: Re-Imagining Indigenous presence in the classroom. Socialist Studies, 9(1), 109-127.

Levstik, L. S., \& Barton, K. C. (2010). Doing history: Investigating with children in elementary and middle schools (4th ed.). Mahwah, NJ: Lawrence Erlbaum.

Littlebear, R. E. Cogent Education (2017), 4: 1371820 Retrieved from https://doi.org/10.1080/2331186X.2017.1371820

Loewen, J. W. (2010). Teaching what really happened: How to avoid the tyranny of textbooks and get students excited about doing history. New York, NY: Teachers College Press.

Loewen, J. W. (1995). Lies my teacher told me: Everything your American history textbook got wrong. New York, NY: Simon \& Schuster.

Lomawaima, K.T. (2004). Educating Native Americans. In J.A. Banks and C.A. McGee Banks (Eds.) Handbook of research on multicultural education ( $2^{\text {nd }}$ edition) (pp. 441-461). San Francisco: Jossey-Bass. 
McCarty, T., \& Lee, T. (2014). Critical Culturally Sustaining/Revitalizing Pedagogy and Indigenous education sovereignty. Harvard Educational Review, 84(1), 101-124.

Mehan, H. Lintz, A., Okamoto, D., \& Wills, J. S. (1995). Ethnographic Studies of Multicultural Education in Classrooms and Schools. In J.A. Banks and C.A. McGee Banks (Eds.) Handbook of research on multicultural education ( $1^{\text {st }}$ edition) (p. 129-144). New York: Macmillan Publishing.

The Montana Experience: Stories from Big Sky Country (2014, Feb 26). Montana Mosaic: Indian boarding schools [Video file]. Retrieved from https://www.youtube.com/watch?v=FOe-x1aUP2o

Office of Public Instruction (OPI), State of Montana (2012). Essential understandings regarding Montana Indians. Retrieved from https://opi.mt.gov/Portals/182/Page\%20Files/Indian\%20Education/Indian\%20Education \%20101/essentialunderstandings.pdf

Office of Public Instruction (OPI), State of Montana (2017). Montana American Indian student achievement data report Fall 2017. Retrieved from https://opi.mt.gov/Portals/182/Page\%20Files/Indian\%20Education/Indian\%20Student $\% 2$ 0Achievement/Docs/Student\%20Data\%20Report\%202017.pdf

Office of Public Instruction (OPI), State of Montana (n.d.). IEFA social studies lesson plans and resources. Retrieved from http://opi.mt.gov/Educators/Teaching-Learning/Indian$\underline{\text { Education/Social-Studies }}$

Paris, D. (2012). Culturally sustaining pedagogy: A needed change in stance, terminology, and practice. Educational Researcher, 41(3), 93-97.

Pewewardy, C. D. (1998). Culturally responsive teaching for American Indian learners. ERIC 
Digest. Retrieved from ERIC database. (ED459981)

Powell, D. (2017). Brother, can you paradigm?: Toward a theory of Pedagogical Content Knowledge in social studies. Journal of Teacher Education, (OnlineFirst, June 6), 1-11. DOI: $10.1177 / 0022487117708553$

Rubin, H., \& Rubin, I. (2005). Analyzing coded data. In H. Rubin \& I. Rubin, Qualitative interviewing: The art of hearing data ( $\left.2^{\text {nd }} \mathrm{Ed}.\right)$ (pp. 224-245). Thousand Oaks, CA: SAGE.

Sanchez, T. R. (2007). The depiction of Native Americans in recent (1991-2004) secondary American history textbooks: How far have we come? Equity \& Excellence in Education, 40(4), 311-320.

Seixas, P. (2007). Popular film and young people's understanding of the history of Native-White relations. In A. S. Marcus (Ed.) Celluloid blackboard: Teaching history with film (pp. 99120). Charlotte, NC: Information Age Publishing.

Shear, S. B., Knowles, R. T., Soden, G. J., \& Castro, A. J. (2015). Manifesting destiny: Re/presentations of Indigenous peoples in K-12 U.S. history standards. Theory \& Research in Social Education, 43(1), 68-101.

Sleeter, C. E., \& Grant, C. A. (2009). Making choices for multicultural education: Five approaches to race, class, and gender. Hoboken, NJ: John Wiley \& Sons.

Smiley, R. \& Sather, S. (2009). Indian education policies in five Northwest Region states (Issues \& Answers Report, REL 2009- No. 081). Washington, DC: US Dept of Education, Institute of Education Sciences, National Center for Education Evaluation and Regional Assistance, Regional Educational Laboratory Northwest. Retrieved from https://ies.ed.gov/ncee/edlabs/regions/northwest/pdf/REL_2009081.pdf 
Smith, L. T. (1999). Decolonizing methodologies: Research and Indigenous peoples. New York: Zed Books.

Stake, R. E. (1995). The art of case study research. Thousand Oaks, CA: SAGE.

Stoddard, J., Marcus, A., \& Hicks, D. (2014). The burden of historical representation: The case of/for Indigenous film. The History Teacher, 48(1), 9-36.

U. S. English Foundation, Inc. Montana. (2016). Retrieved from https://usefoundation.org/

Warhol, L. (2011). Native American language policy in the United States. Center for Applied Linguistics. Heritage Languages in America. Retrieved from https://www.cal.org/heritage/pdfs/briefs/native-american-language-policy.pdf

Whitney, L., Golez, F., Nagel, G., \& Nieto, C. (2012). Listening to voices of practicing teachers to examine the effectiveness of a teacher education program. Action in Teacher Education, 23(4), 69-76.

Wilson, S. (2008). Research is ceremony: Indigenous research methods. Halifax, Canada: Fernwood Publishing. 
Table 1

Indian Education for All Essential Understandings (MOPI, 2012).

\begin{tabular}{|l|l|}
\hline 1 & $\begin{array}{l}\text { There is great diversity among the twelve tribal nations of Montana in their } \\
\text { languages, cultures, histories and governments. Each Nation has a distinct } \\
\text { and unique cultural heritage that contributes to modern Montana. }\end{array}$ \\
\hline 2 & $\begin{array}{l}\text { There is great diversity among individual American Indians as identity is } \\
\text { developed, defined and redefined by entities, organizations and people. A } \\
\text { continuum of Indian identity, unique to each individual, ranges from } \\
\text { assimilated to traditional. There is no generic American Indian. }\end{array}$ \\
\hline 3 & $\begin{array}{l}\text { The ideologies of Native traditional beliefs and spirituality persist into } \\
\text { modern day life as tribal cultures, traditions, and languages are still practiced } \\
\text { by many American Indian people and are incorporated into how tribes } \\
\text { govern and manage their affairs. Additionally, each tribe has its own oral } \\
\text { histories, which are as valid as written histories. These histories pre-date the } \\
\text { "discovery" of North America. }\end{array}$ \\
\hline 4 & $\begin{array}{l}\text { Reservations are lands that have been reserved by the tribes for their own use } \\
\text { through treaties, statutes, and executive orders and were not "given" to them. }\end{array}$ \\
\hline 5 & $\begin{array}{l}\text { There were many federal policies put into place throughout American history } \\
\text { that have affected Indian people and still shape who they are today. Many of } \\
\text { these policies conflicted with one another. Much of Indian history can be } \\
\text { related through several major federal policy periods. }\end{array}$ \\
\hline 6 & $\begin{array}{l}\text { History is a story most often related through the subjective experience of the } \\
\text { teller. With the inclusion of more and varied voices, histories are being } \\
\text { rediscovered and revised. History told from an Indian perspective frequently } \\
\text { conflicts with the stories mainstream historians tell. } \\
\text { separate and independent from the federal and state governments. However, } \\
\text { the extent and breadth of tribal sovereignty is not the same for each tribe. }\end{array}$ \\
\hline 7 & $\begin{array}{l}\text { Inder the American legal system, Indian tribes have sovereign powers, } \\
\text { and }\end{array}$ \\
\hline 5 &
\end{tabular}

